\title{
A proteção da imagem e da vida privada na França*
}

\section{Leonardo Estevam de Assis Zanini ${ }^{* *}$}

Resumo. O presente artigo analisa o surgimento e o desenvolvimento da proteção da imagem e da vida privada na França. Destaca que inicialmente a defesa desses direitos foi obra da jurisprudência, que foi criando regras aplicáveis aos casos concretos. Os tribunais usavam a cláusula geral de responsabilidade civil, pois não havia doutrina desenvolvida sobre direitos da personalidade. Posteriormente a matéria também passou a ser objeto de estudo dos doutrinadores franceses. Diferentemente da Alemanha, que positivou a proteção muito cedo, a França somente regulou esses direitos com a promulgação da Lei 70-643, de 17 de julho de r970, a qual introduziu o direito à intimidade e à vida privada no art.

Fecha de recepción: 77 de agosto de 2017 . Fecha de aceptación: 22 de enero de 2018.

Para citar el artículo: Zanini, L. E. D. A., "A proteção da imagem e da vida privada na França", Revista de Derecho Privado, Universidad Externado de Colombia, n. ${ }^{\circ}$ 34, enero-junio de 2018 , I 57-I 75. DoI: https://doi.org/ı I I 860 I/o I234366.n34.06

** Livre-docente em Direito Civil pela Universidade de São Paulo, São Paulo, Brasil (201 7). Pós-doutorado em Direito Civil pelo Max-Planck-Institut für ausländisches und internationales Privatrecht, Alemanha. Pós-doutorado em Direito Penal pelo Max-Planck-Institut für ausländisches und internationales Strafrecht, Alemanha. Doutor em Direito Civil pela Universidade de São Paulo (2013), com estágio de doutorado na Albert-Ludwigs-Universität Freiburg, Alemanha. Mestre em Direito Civil pela PUC-SP (2010). Bacharel em Direito pela usP (2000). Juiz Federal. Pesquisador do grupo Novos Direitos cnpq/ufscar. Pesquisador do grupo Direito e Desenvolvimento Público da Universidade de Araraquara, Araraquara, Brasil. Foi bolsista da Max-Planck-Gesellschaft e da capes. Foi Delegado de Polícia Federal (2002-2005). Foi Procurador do Banco Central do Brasil (2002). Foi Defensor Público Federal (2002). Foi Diretor da Associação dos Juízes Federais de São Paulo e Mato Grosso do Sul (2006-20 I I). Foi Diretor Acadêmico da Escola de Formação e Aperfeiçoamento de Servidores da Justiça Federal em São Paulo (20I2-20I4). Contato: lezanini@jfsp.jus.br 
9. ${ }^{\circ}$ do Código Civil francês. Tal norma reforçou a tutela da personalidade, mas resta saber se também houve uma melhoria na proteção da imagem na França, o que vamos estudar no presente artigo.

Palavras-chave: direito à imagem, direito à vida privada, direitos da personalidade, responsabilidade civil, Direito francês.

\section{The Protection of the Image and Privacy in France}

Авsтract. This article analyzes the emergence and development of the protection of the image and privacy in France. It emphasizes that initially the defense of these rights was only work of the courts, that created rules applicable to the concrete cases. The courts used the general clause of civil liability, because there was no developed doctrine on personality rights. Subsequently the matter also began to be object of study of the French doctrinators. Unlike Germany, which granted protection very early, France only regulated these rights with the promulgation of the Law 70-643, of $\mathrm{I} 7^{\text {th }}$ July I 970, which introduced the right to privacy in the article 9 of the French Civil Code. This norm reinforced the protection of the personality, but it remains to be seen whether there has also been an improvement in the protection of the image in France, which we will study in this article.

Keywords: Right to image, right to privacy, personality rights, civil responsibility, French law.

\section{La protección de la imagen y de la vida privada en Francia}

Resumen. Este artículo analiza el surgimiento y desarrollo de la protección de la imagen y de la imagen y de la vida privada en Francia. Destaca que inicialmente la defensa de estos derechos fue obra de la jurisprudencia que creó reglas aplicables a los casos concretos. Los tribunales usaban una cláusula general de responsabilidad civil, pues no existía la doctrina sobre los derechos de la personalidad. Posteriormente, la doctrina francesa se ocupó del tema. A diferencia de Alemania, que ofrecía protección ya desde antes, en Francia solo se regularon estos derechos con la promulgación de la Ley 70-643, del i 7 de julio de I970, que incluyó el derecho a la intimidad y a la vida privada en el artículo 9 del código civil francés, reforzando la tutela de la personalidad. Resta por saber si hubo un progreso en la protección de la imagen en Francia, de lo que se ocupa este trabajo.

Palabras clave: derecho a la imagen, derecho a la vida privada, derechos de la personalidad, responsabilidad civil, derecho francés. 
Sumário. Introdução. I. A proteção da personalidade como criação pretoriana. II. A fundamentação doutrinária para a proteção da personalidade. III. A insuficiente proteção da imagem pela responsabilidade civil. Iv. A positivação da tutela da vida privada: a Lei de 17 de julho de I970. v. A polêmica em torno da positivação da tutela da vida privada. vi. $\mathrm{O}$ direito à vida privada seria um direito geral da personalidade? vir. Os dilemas atuais da doutrina e da jurisprudência. Considerações finais. Bibliografia.

\section{Introdução}

A sociedade europeia, até o século xviII, apresentava suas estruturas sociais e modos de vida organizados de tal forma que era difícil a existência de individualismo. A coletividade tinha precedência em relação ao indivíduo, o que afastava a noção de vida privada do cotidiano da sociedade.

O quadro somente começou a sofrer alteração depois da Revolução Francesa, quando os valores, a mentalidade e os costumes burgueses passaram paulatinamente a preponderar, dando espaço a um novo sistema de referência, que tinha a vida privada, a intimidade e o recato como fundamentos ${ }^{\mathrm{I}}$.

Nessa linha, a França foi a precursora do reconhecimento dos direitos individuais, que vieram associados às ideias revolucionárias e também permitiram, muito cedo, a proteção de determinados aspectos da personalidade. Assim, no que toca à tutela da imagem e da vida privada, a evolução francesa pode ser dividida em duas grandes etapas, cujo divisor de águas é a Lei de I 7 de julho de 1970.

Inicialmente, por mais de cem anos, a criação e o desenvolvimento do direito à imagem e da vida privada ficaram a cargo exclusivamente da jurisprudência, que foi progressivamente fixando as regras aplicáveis aos casos concretos, haja vista a ausência de disposições específicas no Código de Napoleão de $1804^{[2]}$.

A situação somente tomou rumo diverso em I7 de julho de I970, com a promulgação da Lei 70-643, que alterou o art. 9. ${ }^{\circ}$ do Código Civil francês, lá introduzindo o direito à intimidade da vida privada. Com a nova previsão legal, que veio a reforçar a tutela da personalidade, resta-nos então saber em que medida também houve uma melhoria na proteção da imagem na França³.

Diante desse quadro, considerando que a doutrina e a jurisprudência brasileiras recorrem diuturnamente às fontes francesas, faz-se necessário um breve estudo histórico acerca do surgimento e da evolução da proteção da imagem na

I Bertrand, A., Droit à la vie privée et droit à l'image, Paris, Litec, I 999, 2.

2 Bartnik, M., Der Bildnisschutz im deutschen und französischen Zivilrecht, Tübingen, Mohr Siebeck, 2004, 28.

3 Ibíd., p. 28. 
França, que passa obrigatoriamente pela compreensão da relação existente com a tutela da vida privada.

\section{A proteção da personalidade como criação pretoriana}

As primeiras decisões francesas tratando de problemas atinentes ao direito à imagem foram publicadas na segunda metade do século XIX e decorreram da mudança de costumes oriunda da Revolução de I 789 . Antes mesmo que fossem explicitadas as noções de direitos da personalidade e de resguardo da vida privada, os magistrados franceses já resolviam casos abrangendo a utilização indevida de retratos e, posteriormente, de fotografias 4 .

Nesse contexto, pode-se afirmar que historicamente a imagem foi o primeiro atributo da personalidade a ser efetivamente protegido pela jurisprudência 5 . De fato, já no ano de I855, por meio de uma ordonnance de référé, o presidente do Tribunal Civil do Sena proibiu a exposição pública de um quadro em que a diretora da congregação católica Soeurs de la Providence tinha sido retratada, pois ela não havia permitido tal utilização de sua imagem ${ }^{6}$.

Três anos mais tarde, em I 858, o mesmo tribunal proferiu a primeira decisão que tratou de forma mais evidente do direito à imagem, também considerada o marco histórico do nascimento desse direito. O caso envolveu um desenho da famosa atriz de teatro Rachel, que foi retratada em seu leito de morte ${ }^{7}$

A corte, ao julgar a demanda, asseverou que ninguém pode, sem o consentimento expresso dos familiares, publicar ou divulgar a fisionomia de uma pessoa em seu leito de morte, mesmo que se trate de uma celebridade ${ }^{8}$. Foi ainda declarado que o direito de se opor a esta reprodução é absoluto, encontrando seu fundamento no respeito à dor dos familiares, visto que o desconhecimento quanto à utilização da imagem lesiona os sentimentos mais íntimos e mais veneráveis da natureza humana9 .

Assim sendo, mesmo diante da ausência de previsão expressa do direito à imagem na legislação, o julgado, baseado no art. I.382 Código Civil francês,

4 Lindon, R., Dictionnaire juridique: les droits de la personnalité, Paris, Dalloz, I983, 103.

5 Saint-Pau, J.-Сh., "Le droit au respect de la vie privée", en Saint-Pau, J.-Ch. (org.), Droits de la personnalité, Paris, LexisNexis, 2013 , 749.

6 Bertrand, Droit à la vie privée et droit à l'image, cit., I33.

7 BaRTNIK, Der Bildnisschutz im deutschen und französischen Zivilrecht, cit., 28.

8 Kayser, P., La protection de la vie privée par le droit, Paris, Economica, I995, I04-105. Transcrevemos o trecho mencionado da decisão: "que nul ne peut, sans le consentement formel de la famille, reproduire et livrer à la publicité les traits d'une personne sur son lit de mort, quelle qu'ait été la célébrité de cette personne".

9 Labbée, X., Condition juridique du corps humain avant la naissance et après la mort, Villeneuve d'Ascq, Septentrion, 2012, I83. 
determinou a proibição da exposição do desenho que tinha sido feito da atriz, bem como sua apreensão ${ }^{\mathrm{IO}}$.

A jurisprudência fixou então, como regra base, a necessidade do consentimento da pessoa retratada para que haja a publicação das imagens, utilizando, para tanto, uma fundamentação, pelo menos em parte, evidentemente situada no âmbito dos direitos da personalidade, ainda que esta categoria fosse à época desconhecida ${ }^{\mathrm{II}}$.

Tal concepção foi confirmada pela mesma corte em I859, no caso Sergent ${ }^{12}$. $\mathrm{E}$ nos anos que se seguiram a tese também foi reconhecida em um arresto da Corte de Cassação, datado de 15 de janeiro de 1864 , bem como foi em muitas outras oportunidades reafirmada por outros tribunais ${ }^{13}$.

O legislador, diante da problemática que vinha se apresentando, consagrou, no art. I I da Lei de I I de maio de I868, uma disposição que tipificava como contravenção toda publicação que expusesse em um periódico, sem o necessário consentimento, fatos da vida privada, conduta que era punida com multa de 500 francos. Entretanto, a norma não permaneceu durante muito tempo em vigor, pois uma decisão da Corte de Cassação, do ano de I874, estendeu seu campo de aplicação a atos praticados fora do domicílio do cidadão, desde que fossem considerados de foro interior e tivessem relação com a liberdade de consciência, o que provocou protestos ${ }^{\mathrm{I}}$.

Os protestos gerados por referida decisão culminaram na aprovação da Lei de 29 de julho de I88I, a qual definia as liberdades e as responsabilidades da imprensa, inclusive com a previsão de delitos de difamação e contra a coisa pública. Na prática, a lei acabou afastando do direito francês, por quase um século, a proteção da vida privada ${ }^{15}$, que somente pôde ser tutelada indiretamente pelas sanções gerais previstas para as condutas difamatórias e injuriosas ${ }^{16}$.

Ainda dentro do período acima mencionado, deve-se destacar o julgamento do caso Eden contra Whistler, ocorrido em I4 de março de I900, que estendeu às pessoas vivas as regras relativas à tutela da imagem. A demanda envolveu a contratação do pintor Whistler pelo nobre inglês William Eden, que encomendou um retrato de sua esposa, pelo qual pagaria um preço entre roo e I 50 guinés ${ }^{17}$.

io Festas, D. D. O., Do conteúdo patrimonial do direito à imagem: contributo para um estudo do seu aproveitamento consentido inter vivos, Coimbra, Coimbra, 2009, 30.

I I BaRTNIK, Der Bildnisschutz im deutschen und französischen Zivilrecht, cit., 29.

I 2 Bertrand, Droit à la vie privée et droit à l'image, cit., p. 2.

I 3 Lindon, Dictionnaire juridique: les droits de la personnalité, cit., I05.

I4 Bertrand, Droit à la vie privée et droit à l'image, cit., 3 .

I 5 Ibíd., p. 3.

i6 Dreyer, E., Droit penal spécial, 2. a ed., Paris, Ellipses, 20 I 2, I97.

I 7 Strowel, A., Droit d'auteur et copyright: divergences et convergences, Paris, LGDJ, I993, 483. 
Diante do preço fixado de forma aberta, o nobre inglês decidiu pagar a quantia mínima, o que foi considerado ofensivo pelo pintor, que se recusou a entregar o quadro a William Eden ${ }^{18}$. Ao analisar a demanda, a Corte de Cassação considerou a natureza especial do contrato de encomenda do retrato, entendendo que se tratava apenas de uma obrigação de fazer, que se resolveria em perdas e danos ${ }^{19}$.

Todavia, para além do problema da entrega do quadro, concluiu-se ainda que o pintor não poderia fazer qualquer uso da obra antes de providenciar modificações que tornassem a pessoa nela retratada irreconhecível. Assim sendo, mesmo não mencionando expressamente o conceito de "direito à própria imagem", o tribunal proibiu que o pintor Whistler explorasse publicamente o retrato em questão, uma vez que nele poderiam ser reconhecidos os traços de Lady Eden ${ }^{20}$.

Por conseguinte, é fácil constatar que as numerosas decisões proferidas até o início do século xx, mesmo diante da ausência de disposição legal e sem mencionarem expressamente o direito à imagem, reafirmaram a regra conforme a qual a reprodução ou a exibição de um retrato estão subordinadas ao consentimento da pessoa representada. Os tribunais, a despeito de consagrarem tal proteção, não tomaram partido no que toca à sua natureza jurídica ${ }^{21}$, não obstante o evidente predomínio de critérios patrimoniais. E isso se explica pelo fato de que a cláusula geral de responsabilidade delitual, prevista no art. I.382 do Código Civil, era tida como suficiente para a resolução dos casos, e, por outro lado, pelo fato de que não havia uma doutrina razoavelmente desenvolvida acerca dos direitos da personalidade.

\section{A fundamentação doutrinária para a proteção da personalidade}

A literatura francesa somente começou a se ocupar da proteção da personalidade no final do século xıx, quando as decisões proferidas desde I 855 já tinham construído uma base bastante sólida em relação à proibição da exposição da imagem sem o consentimento do retratado.

Nessa evolução, é de se observar que as obras de Bazille e Constant (I 883), de Beaussire (I 888), de Roguin (I889) e de Boistel (I889) já faziam referência a direitos que pertenciam à categoria dos direitos da personalidade. Os dois últimos, o suíço Roguin e o francês Boistel, são considerados os primeiros teóricos dos direitos da personalidade em língua francesa. No entanto, seus trabalhos não

I8 Lindon, R., Dictionnaire juridique: les droits de la personnalité, p. 57.

I9 Lucas, A. y Lucas, H.-J., Traité de la propriété littéraire et artistique, 3. ${ }^{a}$ ed. Paris, Litec, 2006, 348-349.

20 Poulllet, E., Traité théorique et pratique de la propriété littéraire et artistique et du droit de représentation, 3. ${ }^{\text {a }}$ ed., Paris, Marchal et Billard, I 908, 242.

2 I Sтröмногм, S., Le droit moral de l'auteur en droit allemand, français et scandinave avec un perçu de l'évolution internationale. Étude de droit comparé. I première partie. L'évolution historique et le mouvement international, t. I, Stockholm, P.A. Nordstedt \& Söners Förlag, I967, 283. 
utilizam a terminologia "direitos da personalidade" e também são voltados mais para o plano da filosofia do direito do que propriamente para o direito positivo ${ }^{22}$.

No referido período o direito à imagem é considerado pela doutrina como um direito absoluto, mais especificamente como um direito de propriedade do homem sobre ele mesmo. Somente no início do século xx é que a concepção patrimonialista começou a perder força, dando lugar a uma realidade vinculada à proteção dos aspectos mais essenciais do ser humano, o que pode ser explicado pela influência da doutrina alemã dos direitos da personalidade ${ }^{23}$.

O mérito de ter definitivamente consolidado a ideia e o conceito dos direitos da personalidade na França é normalmente atribuído a E. H. Perreau. Em seu trabalho intitulado "Des droits de la personnalité", publicado em I 909 na Revue Trimestrielle du Droit Civil, o autor defendeu a existência da nova categoria dos direitos da personalidade, estudou sua natureza jurídica e seu regime, bem como apresentou um extenso catálogo desses direitos ${ }^{24}$, classificando-os em três grupos. Contudo, não chegou, no extenso rol apresentado, a mencionar o direito à imagem $^{25}$.

A inclusão do direito à imagem entre os direitos da personalidade é feita por Henri Fougerol, no trabalho intitulado La figure bumaine et le droit, que veio a público em I9I3. O estudioso, apoiado na doutrina de Gierke, fez em sua tese uma breve apresentação da teoria dos direitos da personalidade, dedicando o seu primeiro capítulo justamente à natureza jurídica do direito à imagem, que classificou como um direito da personalidade. Assim, o trabalho de Fougerol representou, sem dúvida, uma exceção à doutrina francesa do período, que considerava a imagem como um direito de propriedade ou um direito de autor ${ }^{26}$.

O passo seguinte foi dado em I924, quando a noção de direitos da personalidade foi evocada pela primeira vez em um manual de Direito Civil, de autoria de Demogue. Não se tratava, contudo, de um estudo aprofundado, mas sim de

$$
\begin{aligned}
& \text { Ent } \\
& \text { sonation } \\
& \text { parte } \\
& \text { dans }
\end{aligned}
$$

\section{portc} dans les régimes de communaute", o autor demonstra a existência de um certo número de direitos que têm por função imediata e especial garantir a liberdade e a dignidade da pessoa. Bérard coloca dentro desta categoria, além do direito de autor, o direito à honra, o direito ao nome e o direito à fisionomia, demonstrando ainda sua existência no direito positivo e não simplesmente sobre o plano filosófico. Assim sendo, pondera que a obra de Bérard marca uma reviravolta decisiva na história francesa dos direitos da personalidade, sendo espantoso que seu nome não seja mencionado nos estudos dessa matéria (Lucas-Schloetter, Droit moral et droits de la personnalité, t. I, cit., 85-86).

26 Fougerol, H., La figure humaine et le droit, Paris, Arthur Rousseau, I9 I3, passim. 
simples menção a esses direitos em caso de lesão, donde decorreria o direito de reparação ${ }^{27}$.

Os trabalhos que se seguiram não apresentaram evolução considerável e até o final da década de trinta os estudos franceses sobre o tema não foram muito além do reconhecimento das diferentes prerrogativas particulares, estudadas separadamente pela doutrina. Assim, não houve a elaboração de uma verdadeira teoria dos direitos da personalidade. Mesmo as obras mais célebres do período acabaram não admitindo os direitos da personalidade como uma nova categoria de direitos subjetivos ${ }^{28}$.

Somente em I939, com a publicação da tese "Les droits extrapatrimoniaux", de Roger Nerson, é que surgiu na doutrina francesa uma obra que veio tratar de forma mais aprofundada dos aspectos da vida privada e do direito à imagem. $\mathrm{O}$ autor considerou a imagem humana como um direito da personalidade independente, que não se confundia com o direito à honra e à vida privada ${ }^{29}$.

A obra rejeitou, entretanto, a ideia de um direito geral da personalidade, afirmando que tal instituto traria risco de insegurança jurídica e impossibilidade de determinação. Acrescentou ainda que os direitos da personalidade nada mais são do que direitos sancionatórios, o que não autorizava considerá-los direitos subjetivos ${ }^{30}$. Nessa linha, o autor não reconheceu a existência de direitos abstratos, mas apenas conferiu o poder de agir em juízo quando a pessoa sofresse ofensa à integridade corporal, à honra ou à imagem, podendo assim fazer uso da previsão do art. I.382 do Código Civil francês ${ }^{3 \mathrm{I}}$.

Outrossim, quando Nerson se concentrou no estudo da imagem, considerando-a como uma qualidade pessoal do homem, que deve ser defendida diante dos perigos da sua difusão pública, acabou por qualificá-la como um direito extrapatrimonial, não explicando, entretanto, as negociações econômicas dela decorrentes ${ }^{32}$.

No mesmo sentido se manifestou Roubier, em sua obra intitulada Droits subjectifs et situations juridiques, que veio a lume em i963. Segundo o célebre estudioso, os direitos da personalidade não teriam o aspecto ordinário dos direitos subjetivos, já que não se poderia falar na apropriação de elementos como a imagem e a honra. Por isso, afirmou que a personalidade não poderia ser objeto

27 Lucas-Schloetter, Droit moral et droits de la personnalité: étude de droit compare français et allemand, t. I, cit., $87-88$.

28 Ibíd., p. 94 .

29 Adarraga, El derecho a la propia imagen, cit., 80.

30 Capelo de Sousa, R. V. A., O direito geral de personalidade, Coimbra, Coimbra, I995, i 26.

3 I Lucas-Schloetter, Droit moral et droits de la personnalité: étude de droit compare français et allemand, t. I, cit., I33.

32 Adarraga, El derecho a la propia imagen, cit., 8I. 
de direitos, uma vez que todos os direitos são feitos para o homem, que figura necessariamente na posição de sujeito ${ }^{33}$.

Aliás, é de se notar que a incerteza quanto à qualificação dos direitos da personalidade como direitos subjetivos vai perdurar na doutrina francesa praticamente até o final da década de sessenta ${ }^{34}$. Não faltaram, entretanto, aqueles que se pronunciaram a favor da inclusão dos direitos da personalidade como uma nova categoria de direitos subjetivos, como foi o caso de Decocq, na obra Essai d'une théorie générale des droits sur la personne, publicada em I960[35].

Portanto, apesar dos esforços doutrinários, os trabalhos defendendo a existência de direitos da personalidade, tal qual a inclusão do direito à imagem nessa nova categoria, não tiveram aceitação na jurisprudência, sendo raros os casos em que julgados abordaram a temática ${ }^{36}$. Somente após a Segunda Guerra Mundial é que o conceito dos direitos da personalidade foi compreendido pelos tribunais e regularmente utilizado. Assim sendo, pode-se dizer que na primeira metade do século xx o desenvolvimento dos direitos da personalidade na França decorreu de obra da doutrina, o que foi feito de forma independente, ou seja, sem contar, no que toca às inovações, com o apoio da jurisprudência37.

\section{A insuficiente proteção da imagem pela responsabilidade civil}

O passo seguinte do desenvolvimento do direito à imagem na França decorreu das decisões proferidas na década de sessenta. Nesse período houve um aumento vertiginoso do número de processos ajuizados por problemas relacionados com o direito à imagem e à vida privada, especialmente em função de abusos cometidos pela imprensa na captação de imagens de celebridades em espaços reservados, que levaram ao pagamento de indenizações baseadas no art. I.382 do Código Civil ${ }^{8}$.

33 Lucas-Schloetter, Droit moral et droits de la personnalité: étude de droit compare français et allemand, t. I, cit., I33.

34 É interessante observar que a expressão direitos da personalidade somente vai ser empregada pelo legislador francês pela primeira vez na Lei de 4 de janeiro I99 I, relativa às marcas de fábrica, de comércio e serviços, cujo art. $4{ }^{\circ}$ (L. 7 I I-4 CPI) dispõe: "ne peut être adopté comme marque un signe portant atteinte à des droits antérieurs, et notamment: [...] au droit de la personnalité d'um tiers, notamment à son nom patronymique, à son pseudonyme ou à son image" (LuCAs-SCHLOETTER, ob. cit., I 3 I).

35 Decoce, A., Essai d'une théorie générale des droits sur la personne, Paris, LGDJ, I96o, passim.

36 Conforme esclarece Lucas-Schloetter, os julgados no período às vezes qualificavam a imagem como um direito de propriedade, em outros casos, entretanto, preferiam não utilizar o termo "propriedade", mencionando a liberdade que possui a pessoa fotografada ou o direito exclusivo que toda pessoa tem sobre sua imagem ou ainda afirmando que "toda pessoa é senhora de sua efígie e do uso que dela é feito" (Lucas-Schloetter, Droit moral et droits de la personnalité: étude de droit compare français et allemand, cit., I 34 ).

37 BartnIK, Der Bildnisschutz im deutschen und französischen Zivilrecht, cit., 30.

$3^{8}$ Ibíd., 3 I. 
Nesse contexto, dá-se especial relevo aos casos Picasso, Gérard Philippe e Brigitte Bardot, que teriam contribuído decisivamente para forçar o legislador francês a intervir na ordem jurídica para consagrar o que já vinha sendo reconhecido pela doutrina e jurisprudência, isto é, o direito ao respeito da vida privada e da imagem ${ }^{39}$.

Realmente, já no caso Gérard Philippe, em I965, observa-se a utilização, pela primeira vez, do termo "droit de la personnalite" em um julgado $4^{\circ}$. A discussão judicial decorreu do fato de jornalistas terem invadido o quarto de hospital onde estava o filho de Gérard Philippe, um artista bastante famoso, para tirar fotos ${ }^{4}$.

A conduta dos jornalistas deu então ensejo à apreensão do material, o que foi determinado pelo tribunal, pois a publicação das fotos tinha objetivos meramente comerciais, bem como por considerar as informações sobre o estado de saúde do menor como uma invasão intolerável da vida privada ("immixtion intolérable dans la vie privée") $4^{42}$. É interessante notar, entretanto, que o julgado, como costuma acontecer no Direito francês, deu ao direito à imagem a mesma natureza do direito à intimidade 43 .

A atriz Brigitte Bardot e seus filhos, em outro caso envolvendo jornalistas, foram alvo de teleobjetivas quando se encontravam em uma propriedade privada. Em face da invasão de privacidade para a captação das imagens, a atriz obteve sucesso na demanda judicial proposta contra a publicação das fotos, tendo o Tribunal de Grande Instância do Sena declarado que "o simples fato de publicar sem autorização o retrato fotográfico alheio constitui uma falta, cujo autor deve reparação"44.

Vale notar, entretanto, que as duas decisões fundamentaram seu resultado não somente no direito à própria imagem, mas também e principalmente em um outro aspecto da personalidade, ou seja, na proteção do direito à vida privada. Contudo, para se chegar à solução do problema, tanto no que toca ao direito à imagem como em relação à proteção da vida privada, foi necessária a consideração de diversos interesses pessoais protegidos indiretamente pelo direito comum. Desse modo, a tutela dos direitos da personalidade passou obrigatoriamente pela cláusula geral de responsabilidade delitual do art. I.382 do Código Civil francês 45 .

Bertrand, Droit à la vie privée et droit à l'image, cit., 5 .

40 Lucas-Schloetter, Droit moral et droits de la personnalité: étude de droit compare français et allemand, cit., I3 I.

4I Beignier, B., L'bonneur et le droit, Paris, LGDJ, I995, 67.

42 Lindon, Dictionnaire juridique: les droits de la personnalité, cit., I 22.

43 SAHм, R., O direito à imagem na dogmática civil contemporânea, tese de doutorado, Universidade de São Paulo, São Paulo, 2001, 226.

44 BaRTNIK, Der Bildnisschutz im deutschen und französischen Zivilrecht, cit., 3 I.

45 Ibíd., 3 I. 
Seja como for, é importante observar que não obstante a proteção da personalidade ter emergido no século xıx, no âmbito da responsabilidade civil, é certo que a tutela aquiliana demanda a existência de culpa e prejuízo, não sendo, por conseguinte, adaptada e eficaz para a proteção dos casos onde se busca uma tutela preventiva ou uma reparação por dano extrapatrimonial ${ }^{6}$.

Destarte, diante dos inconvenientes e dos avanços técnico-científicos do século xx, que proporcionaram uma crescente ofensa aos bens da personalidade, em particular pela invasão da esfera privada de pessoas famosas pela imprensa, a jurisprudência da década de sessenta se viu obrigada, como vimos, ao reconhecimento dos direitos da personalidade, ainda que não positivados, o que acabou reabrindo a discussão sobre a necessidade de intervenção legislativa.

\section{A positivação da tutela da vida privada: a Lei de 17 de julho de 1970}

A necessidade de positivação dos direitos da personalidade já era uma preocupação dos estudiosos na década de I950, quando um projeto de reforma do Código Civil, no título relativo ao estado das pessoas físicas, dedicou ao tema um capítulo inteiro, que continha I 8 artigos (arts. I48 a I65) 47 . A proposta ainda se posicionou a favor do reconhecimento de um direito geral da personalidade $4^{8}$.

Apesar da não aprovação do referido projeto, nele já podia ser testemunhada a importância dada na época aos direitos da personalidade, em especial se considerarmos os estudos que lhes foram consagrados em i946 e r959 pela Associação Henri Capitant. Dessas pesquisas também veio a fórmula de Savatier, que em I 959 já falava da ascensão da pessoa ao centro do direito contemporâneo49.

Entretanto, somente na década de I970, depois dos tribunais terem julgado, na década anterior, uma grande quantidade de demandas envolvendo direitos da personalidade, é que o legislador francês positivou o direito ao respeito da vida privada $^{5}$, o que foi feito pela Lei $70-643$, de 17 de julho de 1970.

A referida lei tinha o objetivo de reforçar a garantia dos direitos individuais dos cidadãos, apresentando duas partes, com inovações tanto na esfera civil como na tutela penal, o que é relativamente comum no sistema jurídico francês ${ }^{5 \mathrm{I}}$.

46 Legler, T., La vie privée, image volée: la protection pénale de la personnalité contre les prises de vues, Berna, Staempfli, I997, 94.

47 Lucas-Schloetter, Droit moral et droits de la personnalité: étude de droit compare français et allemand, cit., I 3 I.

48 Beignier, L'bonneur et le droit, cit., 54 .

49 Lucas-Schloetter, Droit moral et droits de la personnalité: étude de droit compare français et allemand, cit., I 32 .

50 Legler, La vie privée, image volée: la protection pénale de la personnalité contre les prises de vues, cit., 95 .

5 I Bartnik, Der Bildnisschutz im deutschen und französischen Zivilrecht, cit., p. 33. 
A mais importante inovação da lei foi a introdução do direito à vida privada, que passou a ser um direito subjetivo expressamente reconhecido pelo legislador. Para tanto, a redação do art. 9. ${ }^{\circ}$ do Código Civil foi alterada, passando a prever que "Cada um tem direito ao respeito de sua vida privada" ${ }^{2}$.

\section{A polêmica em torno da positivação da tutela da vida privada}

O mérito da introdução da tutela da vida privada no art. $9{ }^{\circ}$ do Código Civil não é, contudo, questão pacificada. Ainda hoje existem autores que consideram essa previsão desprovida de qualquer utilidade ${ }^{53}$, uma vez que não passaria de uma dissimulação da aplicação das regras tradicionais da responsabilidade civil e do Direito Penal. As críticas também dizem respeito à determinação desses direitos e de seu conteúdo. Outros civilistas, por seu turno, colocam em dúvida a própria existência dos direitos da personalidade, argumentando que essa matéria não tem coerência doutrinária e nem maturidade legislativa ${ }^{54}$.

No âmbito do Direito Internacional, aponta-se que a vida privada já estaria protegida pelo art. I 2 da Declaração Universal de Direitos Humanos, de ıo de dezembro de I948. Também se destaca que a França ratificou a Convenção Europeia dos Direitos do Homem (CEDH), de 4 de novembro de I950, cujo art. $8 .^{\circ}$, I tem redação praticamente idêntica à da que foi introduzida no art. $9 .^{\circ}$ do Código Civil55.

Por outro lado, em relação ao direito interno, acrescenta-se que não obstante a Constituição francesa de $195^{8}$ não tratar diretamente da matéria, na jurisprudência constitucional já se entendia que a proteção da vida privada comporia o núcleo da "liberdade individual", de modo que tal direito poderia ser compreendido como expressão desse princípio constitucional ${ }^{5}$. Ademais, havia ainda aqueles que asseveravam que a previsão seria uma fonte de dificuldades, haja vista problemas decorrentes da determinação do próprio conteúdo do direito à vida privada, bem como aduziam que o direito francês já consagrava o princípio de que toda culpa obriga seu autor à reparação do dano causado57.

Todavia, a despeito dos argumentos contrários, é certo que a introdução do direito à vida privada no Código Civil outorgou fundamentação normativa às ações ajuizadas. Assim, não era mais necessário o recurso exclusivo ao art. I.382

LEGLER, La vie privée, image volée, cit., 94.

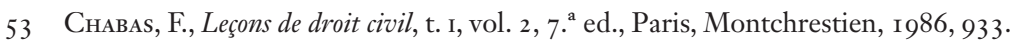

54 Bertrand, Droit à la vie privée et droit à l'image, cit., 6.

55 Bartnik, Der Bildnisschutz im deutschen und französischen Zivilrecht, cit., 33-34.

56 Ibíd., 33-34.

57 KAYser, La protection de la vie privée par le droit, cit., I 23. 
do Código Civil, o que também contribuiu para a melhoria da segurança jurídica $^{5}$.

Outrossim, além do expresso reconhecimento desse direito subjetivo, temos ainda a previsão da segunda parte do art. 9. ${ }^{\circ}$ do Código Civil, que para muitos seria até mais importante. Nela são previstas medidas judiciais preventivas para a proteção da vida privada, que anteriormente apenas contava com uma tutela repressiva e com a ousadia de alguns julgados, que tomavam medidas corajosas, mas passíveis de discussão no âmbito da dogmática, ante a ausência de disposição legal59.

De qualquer forma, o certo é que a proclamação inserida no artigo em questão acabou por consolidar as soluções anteriormente propostas pela jurisprudência e, ao mesmo tempo, permitiu novos desenvolvimentos, entre os quais podemos destacar as discussões atinentes à existência de uma fórmula geral para a proteção da personalidade ${ }^{60}$.

\section{O direito à vida privada seria um direito geral da personalidade?}

A abrangência do direito à vida privada é bastante discutida na França. Existe a tendência de um grande número de estudiosos de englobar a maioria dos direitos da personalidade no direito à vida privada. Isso se explica pela preocupação de se encontrar fundamento legislativo para as diversas manifestações da personalidade ${ }^{6 \mathrm{I}}$.

Com efeito, a partir da ideia de que a privacidade é composta por uma multiplicidade de informações pessoais, como o nome, o endereço, a voz e a própria imagem, considerar-se-ia que o direito ao respeito à vida privada, previsto no art. 9. ${ }^{\circ}$ do Código Civil, tenderia a se tornar uma espécie de direito geral da personalidade.

Nesse contexto, como o direito previsto no art. $9 .^{\circ}$ do Código Civil corresponderia a um domínio sobre informações pessoais, e como a imagem faria parte de tais informações, não haveria nenhum outro significado para a imagem fora

$5^{8}$ BartniK, Der Bildnisschutz im deutschen und französischen Zivilrecht, cit., 34.

59 Traduzimos livremente a segunda parte do art. 9. ${ }^{\circ}$ do Código Civil francês: "Os juízes podem, sem prejuízo da reparação do dano sofrido, prescrever todas medidas, tais como sequestro, apreensão e outras, próprias para impedir ou fazer cessar um atentado à intimidade da vida privada: estas medidas podem, se houver urgência, ser ordenadas provisoriamente". Transcrevemos o original: "Les juges peuvent, sans préjudice de la réparation du dommage subi, prescrire toutes mesures, telles que séquestre, saisie et autres, propres à empêcher ou faire cesser une atteinte à l'intimité de la vie privée: ces mesures peuvent, s'il y a urgence, être ordonnées en référê".

6o Carbonnier, J., Droit civil. Introduction. Les personnes, I4. ${ }^{\text {a }}$ ed., Paris, PUf, I 982, 340.

6I Goubeaux, Traité de droit civil: Les personnes, cit., 273. 
do direito à vida privada ${ }^{62}$. Assim, em uma interpretação extensiva da disposição em questão, a imagem seria apenas um meio para uma lesão particularmente grave da vida privada ${ }^{6} 3$. Haveria então um atentando à vida privada por intermédio da imagem, entendimento que certa parte da doutrina afirma ser preferível à análise de uma série de diversos direitos da personalidade, tradicionalmente reconhecidos na França ${ }^{64}$.

De fato, na medida em que a ideia de intimidade invoca o que o indivíduo tem de mais profundo e garante a exclusão de terceiros, não causa grande surpresa a absorção de muitos direitos da personalidade pelas noções de vida privada. Todavia, essa concepção abrangente do direito ao respeito à vida privada cria mais confusão, tornando sem efeito qualquer tentativa de se precisar a expressão ${ }^{65}$.

Ante as dificuldades, parte da doutrina entendeu que a melhor técnica era não permitir a expansão da qualificação da vida privada, de modo que não se admitiria na França a introdução de um direito geral da personalidade ${ }^{66}$.

A jurisprudência, por outro lado, considerando os problemas gerados pela interpretação restritiva do espectro de atuação da previsão do art. 9. ${ }^{\circ}$ do Código Civil, tem admitido a ampliação da tutela do direito à vida privada ${ }^{67}$, sancionando, de forma geral, qualquer atentado intolerável à personalidade, notadamente aqueles praticados pela imprensa ${ }^{68}$.

Assim sendo, tal entendimento integra a proteção de muitos direitos da personalidade no âmbito da vida privada, o que tem se verificado especialmente no que toca à imagem, que tem sido considerada, até mesmo em decisões mais recentes da Corte de Cassação, como expressão do art. 9. ${ }^{\circ}$ do Código Civil ${ }^{69}$.

Por conseguinte, a despeito das dificuldades geradas pela legislação, que não prevê nenhuma disposição que proteja expressamente o direito à própria imagem, é certo que a jurisprudência tem salvaguardado, de forma geral, as situações de atentado intolerável à personalidade. Para tanto, os magistrados têm partido do estabelecido no art. 9. ${ }^{\circ}$ do Código Civil, o que tem permitido a tutela da imagem, particularmente quando há ofensa por parte da imprensa ${ }^{70}$. Portanto, poder-se-ia dizer que a jurisprudência francesa vê o direito à vida privada como

Bartnik, Der Bildnisschutz im deutschen und französischen Zivilrecht, cit., $3^{8}$.

63 Beignier, L'bonneur et le droit, cit., 68.

64 Goubeaux, Traité de droit civil: Les personnes, cit., 273.

65 Ibíd., p. 273.

66 Beignier, L'bonneur et le droit, cit., 54.

67 HeIsig, C., Persönlichkeitsschutz in Deutschland und Frankreich, Hamburg, Dr. Kovac, I999, 74

68 Beignier, L'bonneur et le droit, cit., 54.

69 Bartnik, Der Bildnisschutz im deutschen und französischen Zivilrecht, cit., 39.

70 Hengst, F., Der strafrechtliche Schutz des Rechts am eigenen Bild (\$ 2ora StGB), Frankfurt a.M., Peter Lang, 20I 2, 201 . 
a norma fundamental para a proteção da personalidade, quase um direito geral da personalidade ${ }^{7 \mathrm{I}}$.

\section{Os dilemas atuais da doutrina e da jurisprudência}

A doutrina francesa das décadas de 1970 e i980 adotou as concepções tradicionais, sem inovações consideráveis, definindo os direitos da personalidade essencialmente em oposição aos direitos patrimoniais, visto que os considerava como direitos não patrimoniais, fora do comércio, intransmissíveis, impenhoráveis e imprescritíveis $^{72}$.

$\mathrm{O}$ direito à imagem, nesse momento, já era considerado pela maior parte dos estudiosos franceses como um direito da personalidade, o mesmo podendo ser dito em relação ao direito à vida privada, variando a doutrina apenas no que toca ao rol de direitos protegidos.

Entretanto, a concepção tradicional dos direitos da personalidade não via espaço para a existência de aspectos patrimoniais, o que não se coadunava com o reconhecimento da exploração econômica de muitas manifestações da personalidade, como é o caso da imagem, da voz, do nome e da vida privada. Assim, a exploração econômica dos direitos da personalidade, ainda que admitida com ressalvas, iniciou um novo ciclo de debates, o que levou a novos questionamentos por parte da doutrina e da jurisprudência ${ }^{73}$.

$\mathrm{Na}$ tentativa de dar uma resposta a esse fenômeno econômico, o Direito francês acabou criando outros problemas, pois tentou enquadrar o direito à imagem em outras categorias que permitem a exploração econômica, reabrindo novamente o debate em torno da natureza jurídica do direito à imagem, o que tem gerado enorme confusão na doutrina e jurisprudência.

Nessa linha, há quem afirme que o direito à imagem e à vida privada constituem novos direitos conexos ou vizinhos ao direito de autor, apresentando vários pontos em comum, semelhanças essas que acabam sendo maximizadas pela própria evolução dos costumes e pelos avanços tecnológicos, que facilitam a substituição do texto pela imagem.

Realmente, se consideramos que há um grande comércio envolvendo a exposição de imagens e de informações sobre a vida pessoal de celebridades, bem como que a exploração desse mercado pela forma de licenças ou contratos relacionados com o direito ao nome e à imagem gera muito dinheiro, fica fácil entender aqueles que identificam na imagem a figura de um novo direito conexo.

A reviravolta pode ser facilmente notada na doutrina mais recente, que muitas vezes retrocede e coloca novamente em dúvida a existência de um direito

7 I BaRtniK, Der Bildnisschutz im deutschen und französischen Zivilrecht, cit., 39.

72 Bertrand, Droit à la vie privée et droit à l'image, cit., 7 .

73 Ibíd., 7-8. 
autônomo à imagem. Acquarone, por exemplo, acredita ser artificial a distinção entre o direito à imagem e os outros direitos da personalidade, considerando que a imagem, como instrumento de comunicação, é um meio de atentar contra direitos da personalidade, entre os quais destaca o respeito à vida privada e à honra. Por isso, entende que a autonomia do direito à imagem é uma concepção bastante frágil74.

Beignier, por seu turno, fazendo uma análise da jurisprudência francesa sobre o direito à imagem, chega à conclusão de que tal direito se confunde com um atentado à tranquilidade da vida privada, não existindo, por consequência, um direito à imagem autônomo. A tutela extrapatrimonial da imagem faria então, conforme entendimento do referido autor, parte de um direito mais amplo, o direito fundamental à proteção da tranquilidade e da dignidade ${ }^{75}$, enquanto que a proteção patrimonial da imagem representaria uma variante da propriedade $\operatorname{artística~}^{76}$.

Seguindo tal linha de raciocínio, parte da doutrina moderna e numerosas decisões mais recentes aceitam a existência de uma natureza dupla do direito à imagem, que comportaria dois elementos distintos, no que se poderia falar em uma aproximação do direito francês ao direito americano. Assim sendo, o direito patrimonial à imagem, considerado uma espécie de propriedade, seria assemelhado ao right of publicity. $\mathrm{O}$ direito extrapatrimonial à imagem, por seu turno, guardaria proximidade com o right of privacy 77 .

Outrossim, a dualidade ainda permitiria o surgimento de uma outra distinção, relativa ao fato de se invocar o direito à imagem de forma ativa ou defensiva. Na primeira situação o fundamento da tutela estaria na existência de um atentado ao direito da personalidade, que permitiria a proibição da sua exploração comercial não autorizada por terceiros. No segundo caso, por outro lado, a fixação da imagem configuraria um atentado à vida privada e ao direito de tranquilidade $^{78}$.

A Corte de Cassação, por seu turno, em casos relativamente recentes, tem julgado que o atentado ao respeito devido à vida privada e o atentado ao direito à imagem constituem fontes de prejuízo diferentes. Assim, reconheceu a Corte nesses julgados a existência não somente de prejuízos distintos, mas também de diversos direitos, pelo que mesmo uma imagem banal, tirada em um local público, em princípio necessitaria do consentimento da pessoa para ser difundida79. $\mathrm{Na}$ doutrina recente também encontramos a defesa de tal posicionamento, com

BeIgNier, L'bonneur et le droit, cit., 74 .

75 Lemmens, K., La presse et la protection juridique de l'individu, Bruxelas, Larcier, 2004, 4I 8.

76 Bertrand, Droit à la vie privée et droit à l'image, cit., I35.

77 Ibíd., I36.

78 Ibíd., I 37 .

79 Hassler, T., Le droit à l'image des personnes: entre droit de la personnalité et propriété intellectuelle, Paris, LexisNexis, 20I4, Io. 
o reconhecimento da autonomia do direito à imagem mesmo frente a atentados à vida privada ${ }^{80}$.

\section{Considerações finais}

Conforme foi verificado, o desenvolvimento do direito à imagem na França se deu sem a existência de um texto expresso, não existindo verdadeiramente uma lei em matéria de direito à imagem, visto que a Lei de I7 de julho de 1970 somente sanciona o fato de fotografar uma pessoa se houver atentado à vida $\operatorname{privada}^{8 \mathrm{r}}$.

Por outro lado, também não se pode deixar de notar que mais recentemente a doutrina e a jurisprudência francesas estão bastante divididas, uma vez que ao lado daqueles que veem o direito à imagem como um direito da personalidade, outros têm atribuído uma natureza ambígua a esse direito, desconstruindo, a nosso ver, todos os avanços até então alcançados, tornando o estudo da temática totalmente incoerente.

De qualquer modo, não obstante o silêncio do legislador em relação ao direito à imagem, deve-se destacar que tal fato não impediu a Corte de Cassação francesa de proclamar o art. 9..$^{\circ}$ do Código Civil como fundamento para a tutela da imagem, deixando claro que "toda pessoa tem sobre sua imagem um direito exclusivo e absoluto e pode se opor a sua fixação, a sua reprodução ou a sua utilização sem autorização prévia" ${ }^{82}$.

\section{Bibliografia}

Adarraga, A. A., El derecho a la propia imagen: su identidad y aproximación al derecho a la información, 2. ${ }^{a}$ ed., México, Universidad Iberoamericana, I 998.

Bartnik, M., Der Bildnisschutz im deutschen und französischen Zivilrecht, Tübingen, Mohr Siebeck, 2004.

Beignier, B., L'bonneur et le droit, Paris, LgDJ, I995.

Bertrand, A., Droit à la vie privée et droit à l'image, Paris, Litec, I999.

Capelo de Sousa, R. V. A., O direito geral de personalidade, Coimbra, Coimbra, I 995 .

80 Teyssié, B., Droit civil: les personnes, i 2. .a ed., Paris, Litec, 20 го, 68.

8I Bertrand, Droit à la vie privée et droit à l'image, cit., I 34 .

82 SaInt-PaU, "Le droit au respect de la vie privée", cit., 749. 
Carbonnier, J., Droit civil. Introduction. Les personnes, I4. a ed., Paris, Puf, I982.

Chabas, F., Leçons de droit civil, t. I, vol. 2, 7. . ed., Paris, Montchrestien, I986.

Decoce, A., Essai d'une théorie générale des droits sur la personne, Paris, LGDJ, I96o.

Dreyer, E., Droit penal spécial, 2. a ed., Paris, Ellipses, 20 I 2.

Festas, D. D. O., Do conteúdo patrimonial do direito à imagem: contributo para um estudo do seu aproveitamento consentido inter vivos, Coimbra, Coimbra, 2009.

Fougerol, H., La figure bumaine et le droit, Paris, Arthur Rousseau, I9I3.

HAssler, T., Le droit à l'image des personnes: entre droit de la personnalité et propriété intellectuelle, Paris, LexisNexis, 2014.

HeIsig, C., Persönlichkeitsschutz in Deutschland und Frankreich, Hamburg, Dr. Kovac, I999.

Hengst, F., Der strafrechtliche Schutz des Rechts am eigenen Bild (\$ 2ora StGB), Frankfurt a.M., Peter Lang, 2012.

Kayser, P., La protection de la vie privée par le droit, Paris, Economica, I995.

LABвÉE, X., Condition juridique du corps humain avant la naissance et après la mort, Villeneuve d'Ascq, Septentrion, 2012.

Legler, T., La vie privée, image volée: la protection pénale de la personnalité contre les prises de vues, Berna, Staempfli, I997.

Lemmens, K., La presse et la protection juridique de l'individu, Bruxelas, Larcier, 2004 .

Lindon, R., Dictionnaire juridique: les droits de la personnalité, Paris, Dalloz, I983.

Lucas, A. y Lucas, H.-J., Traité de la propriété littéraire et artistique, 3. ${ }^{a}$ ed. Paris, Litec, 2006.

Lucas-Schloetter, A., Droit moral et droits de la personnalité: étude de droit compare français et allemand, t. I, Aix-en-Provence, PUAM, 2002. 
Pouillet, E., Traité théorique et pratique de la propriété littéraire et artistique et du droit de représentation, $3 .^{\mathrm{a}}$ ed., Paris, Marchal et Billard, I908.

SAHм, R., O direito à imagem na dogmática civil contemporânea, tese de doutorado, Universidade de São Paulo, São Paulo, 200 I.

Saint-Pau, J.-Ch., "Le droit au respect de la vie privée", en SaInt-Pau, J.-Ch. (org.), Droits de la personnalité, Paris, LexisNexis, 2013.

Sтвӧмнодм, S., Le droit moral de l'auteur en droit allemand, français et scandinave, avec un perçu de l'évolution internationale. Étude de droit comparé, t. I, L'évolution bistorique et le mouvement international, t. I, Stockholm, P.A. Nordstedt \& Söners Förlag, I967.

Strowel, A., Droit d'auteur et copyright: divergences et convergences, Paris, LGDJ, I993.

Teyssié, B., Droit civil: les personnes, I 2. ' ed., Paris, Litec, 20 Iо.

ZANini, L. E. D. A., A tutela autônoma do direito à imagem: do surgimento da fotografia à sociedade da informação, tese de livre-docência, Universidade de São Paulo, São Paulo, 20 i6.

Zanini, L. E. D. A., Direito de autor, São Paulo, Saraiva, 2015.

Zanini, L. E. D. A., Direitos da personalidade: aspectos essenciais, São Paulo, Saraiva, 2OII. 